\title{
Recent Advances in Thymidine Kinase 2 (TK2) Inhibitors and New Perspectives for Potential Applications
}

\author{
Eva-María Priego $^{\#}$ *, Anna Karlsson ${ }^{\diamond}$ Federico Gago ${ }^{\S}$, María-José Camarasa ${ }^{\#}$, Jan Balzarini ${ }^{\dagger}$ and María-Jesús \\ Pérez-Pérez ${ }^{\#}$
}

${ }^{\#}$ Instituto de Química Médica (IQM-CSIC), Juan de la Cierva 3, E-28006 Madrid, Spain; ${ }^{\diamond}$ Department of Laboratory Medicine, Karolinska Institute, Huddinge University Hospital, SE-14186 Stockholm, Sweden; ${ }^{\S}$ Departamento de Farmacología, Universidad de Alcalá, Alcalá de Henares, E-28871 Madrid, Spain; ${ }^{\dagger}$ Rega Institute for Medical Research, KU Leuven, B-3000 Leuven, Belgium

\begin{abstract}
Thymidine kinase 2 (TK2), encoded on chromosome 16q22 of the human genome, is a deoxynucleoside kinase (dNK) that catalyzes the phosphorylation of the pyrimidine deoxynucleosides 2'-deoxythymidine (dThd), 2'-deoxyuridine (dUrd) and 2'deoxycytidine ( $\mathrm{dCyd}$ ) to the corresponding deoxynucleoside 5'-monophosphate derivatives. In contrast to the S-phase-specific thymidine kinase 1 (TK1), TK2 is constitutively expressed in the mitochondria and plays an important role in providing dNTPs for the replication and maintenance of mitochondrial DNA (mtDNA). The severe mitochondrial DNA depletion syndrome (MDS) has been associated with mutations in TK2, resulting in mtDNA depletion, isolated skeletal myopathy, and death of the individual at an early stage of life. Some antiviral nucleoside analogs, such as 3'-azido-dThd (AZT) that is targeting the human immunodeficiency virus (HIV)-encoded reverse transcriptase, are substrates for TK2 and it has been proposed that the mitochondrial toxicity observed after prolonged treatment with such drugs could be due to their interaction with TK2. Therefore, the design of specific TK2 inhibitors may be useful to investigate the role of TK2 in the maintenance and homeostasis of mitochondrial dNTP pools and its contribution to the mitochondrial toxicity of several antiviral and anticancer drugs. Since 2000, several potent and selective TK2 inhibitors have been described. Besides bringing together previously reported inhibitors, special attention will be paid in this review to the new families of TK2 inhibitors more recently described, together with modeling studies and biological assays. Moreover, the last section will be focused on several recent investigations that suggest that depletion of mtDNA can take place both in tumorigenesis and during cancer treatment with certain nucleoside analogues.
\end{abstract}

Keywords: Mitochondrial thymidine kinase 2 (TK2), nucleoside metabolism, enzymatic inhibitors, mitochondrial depletion syndrome (MDS), tumorigenesis

\section{INTRODUCTION}

In mammalian cells, the pyrimidine nucleoside thymidine (dThd) (1, Fig. 1) can be phosphorylated to its corresponding 5'monophosphate (dTMP, 2) by two different enzymes: thymidine kinase 1 or TK1, and thymidine kinase 2 , also referred to as mitochondrial thymidine kinase or TK2 [1,2]. The phosphate group that is transferred to the $5^{\prime}-\mathrm{OH}$ of thymidine is derived, in general, from ATP, although other nucleoside triphosphates can also act as phosphate donors. The reaction is performed in the presence of $\mathrm{Mg}^{2+}$. Both enzymes belong to the family of deoxynucleoside kinases (dNKs) and are involved in the pyrimidine nucleoside salvage pathway. dNKs are instrumental in the activation of a variety of nucleoside analogues [3, 4]. These agents represent a drug family extensively studied for therapeutic applications mostly against the proliferation of cancer cells and virus replication. Their chemotherapeutic properties have, more recently, also been evaluated against bacterial, parasitic and protozoal infections.

Despite their similar role in thymidine phosphorylation, the differences between TK1 and TK2 are very pronounced in view of their cellular localization, encoding genes, primary sequence, levels of expression according to the cell type and/or phase of the cell cycle, capacity to recognize nucleoside analogues besides their natural substrate, etc. Even their complex regulation shows significant differences [5].

Human TK1 (hTK1) was cloned and characterized in the eighties and the encoding gene is located at chromosome $17 q 25[6,7]$. TK1 has a cytosolic localization and its expression is strongly cellcycle dependent. High enzyme levels are detected during the $G_{1} / S$ phase of the cell cycle while they decrease during the $G_{2} / M$ phase

*Address correspondence to this author at the Instituto de Química Médica (C.S.I.C.), C/Juan de la Cierva, 3, E-28006 Madrid, Spain;

Tel: 34-91-5680040; Fax: 34-91-5644853; E-mail: empriego@iqm.csic.es and are absent in non-proliferating (resting) cells. Interestingly, TK1 levels are high in several proliferating and malignant cells even up to 15-fold compared to normal cells and therefore are considered as a marker with prognostic value for certain tumors [8-10]. From an amino acid sequence point of view, hTK1 has no close structural congeners. Concerning substrate recognition (Fig. 2), TK1 phosphorylates dThd (1) and dUrd (3) (but not dCyd (4)) among the natural substrates and some nucleoside analogues such as 3'-azido-dThd (AZT) (5a) and 3'-fluoro-dThd (FLT) (5b). Both drugs are highly active against HIV [11] (Fig. 2), and AZT and FLT are excellent substrates for TK1 [12].

Both $h T K 1$ and $T K 2$, the latter gene being cloned in the late nineties $[13,14]$, are expressed from a nuclear gene located at chromosome 16q22. The enzyme contains an N-terminal mitochondrial targeting sequence and is imported into the mitochondria, its final localization. The levels of TK2 are not cell-cycle regulated. It is a constitutively-expressed enzyme regardless of the cell cycle. In proliferating cells, although TK2 is expressed, the levels of hTK1 are much higher (>10- to 20-fold) than those of TK2. Therefore the contribution of TK2 to cellular deoxynucleoside phosphorylation is rather marginal in such cells. However, in resting (post-mitotic) cells, TK2 is the predominant, if not the exclusive nucleoside kinase able to phosphorylate all natural pyrimidine deoxynucleosides (i.e. thymidine (1), deoxyuridine (3) and deoxycytidine (4)). Interestingly, TK2 is also able to recognize as substrates a variety of nucleoside analogues with antiviral and/or anticancer properties such as 1- $\beta$-D-arabinofuranosylthymine (AraT) (6), 1- $\beta$-D-(2'fluoroarabinofuranosyl)-5-iodouracil (FIAU) (7) and, particularly (E)-5-(2-bromovinyl)-2'-dUrd (BvdU) (8) (Fig. 2) [14]. The antiHIV drug AZT (5a) is quite a poor substrate for TK2, but in nondividing cells TK2-catalysed phosphorylation of AZT becomes relevant $[15,16]$.

On the basis of its amino acid sequence, the enzyme that most closely resembles TK2 is the multisubstrate deoxynucleoside kinase 
<smiles>Cc1cn(C2CC(O)C(CO)O2)c(=O)[nH]c1=O</smiles>

$1 \mathrm{dThd}$

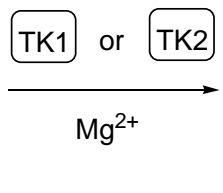

(1)<smiles>Cc1cn(C2CC(O)C(COP(=O)([O-])O)O2)c(=O)[nH]c1=O</smiles>

2 dTMP

Fig. (1). Thymidine phosphorylation reaction catalyzed by TK1 and TK2.<smiles>O=c1ccn(C2CC(O)C3OCC2O3)c(=O)[nH]1</smiles>

3 dUrd<smiles>[R]C1CC2OC1C2n1cc(C)c(=O)[nH]c1=O</smiles>

5 a $\mathrm{R}=\mathrm{N}_{3}, \mathrm{AZT}$

5b $R=F, F T L$

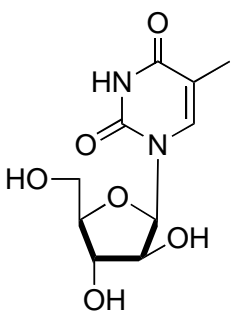

6 AraT<smiles></smiles>

4 dCyd

Fig. (2). Representative substrates of TK2.

of the fruitfly, Drosophila melanogaster (Dm-dNK), with a sequence identity of $\sim 48 \%$, and to a lesser extent, the thymidine kinase encoded by herpes simplex virus type 1 (HSV-1 TK). Interestingly, these two enzymes, which are more divergent in their sequence but have a similar 3D-structure [17], recognize a broad range of substrates, a characteristic that is also present in TK2.

Due to their differences in expression (depending the cell cycle) and localization (cytosol/mitochondria), TK1 and TK2 differently contribute to the phosphorylation of dThd and its analogues. In proliferating cells, the contributions of TK1 and ribonucleotide reductase (which converts ribonucleotides to 2'-deoxyribo-nucleotides) and thymidylate synthase (that converts 2'-dUMP to 2'dTMP) are sufficient to provide the required dThd-5'-triphosphate (dTTP) pools [18]. But in resting cells the picture is significantly different. It is interesting to mention that mitochondrial DNA (mtDNA) undergoes turnover in post-mitotic cells while nuclear DNA does not [19]. This turnover requires a continuous dNTP demand and balanced dNTP pools. Mitochondrial TK2 and deoxyguanosine kinase (dGK) are the two sole nucleoside kinases that catalyze the first activation step for all natural nucleosides, and eventually control the mtDNA synthesis rate [20]. The importance of TK2 activity for mtDNA maintenance has indeed been demonstrated in a mouse model deficient in TK2 [21], as will be discussed later.

TK2 is also involved in mitochondrial DNA depletion syndrome (MDS), a clinically heterogeneous group of mitochondrial disorders characterized by a reduction of the mtDNA copy number in affected tissues without mutations or rearrangements in the
mtDNA [22]. Among the causes directly involved in the appearance of MDS are mutations in the gene encoding TK2. The first reported cases of patients with a TK2 deficiency suffered from severe myopathy $[23,24]$. Since then, more than 20 different pathologies associated to TK2 mutations have been described. While weakness and hypotonia are common symptoms, hepatopathy and/or encephalopathy have also been reported $[25,26]$. Interestingly, similar symptoms have been described in patients exposed to prolonged treatment with nucleoside analogues [27].

With the information provided so far it is likely that TK2 plays a role in mtDNA synthesis particularly in non-proliferating cells and therefore TK2 inhibitors can be considered as valuable tools to study the role of TK2 in the maintenance and homeostasis of mitochondrial nucleotide pools and mtDNA. Moreover, specific TK2 inhibitors may also be useful to determine the involvement of TK2 in the mitochondrial toxicity of a number of antiviral and anticancer drugs, or to investigate the contribution of TK1 and TK2 to thymidine phosphorylation in different cell types.

Since 2000, several research groups have been working on the design, synthesis and evaluation of specific TK2 inhibitors, as reviewed in 2005 [28] and later on in 2008 [29]. In the present review article attention has been paid to the most relevant compounds described up to 2008 and to the novel compound families described since then. Also, computer-assisted molecular modeling studies to explain the interactions between the inhibitors and their target enzyme TK2, will be addressed here. In the last section, the importance of TK2 in mtDNA maintenance will be further illustrated, 
including very recent findings that suggest an important role of mtDNA and TK2 in tumorigenesis.

\section{Chemical Structures of TK2 Inhibitors: from Nucleosides to Acyclic Nucleoside Analogues and Back to Nucleosides}

There is no doubt that the availability of human recombinant TK2 to perform enzymatic assays has allowed the identification of a variety of compounds capable of inhibiting TK2 activity. Besides, the similarities between TK2 and other related enzymes such as Dm-dNK and HSV-1 TK have driven the design, synthesis and evaluation of new chemical entities against these enzymes in parallel, trying to rationally explore similarities and differences among them.

In 1999, different nucleosides with modifications on the sugar moiety were tested as substrates or inhibitors of different human deoxynucleoside kinases including dCK, TK1 and TK2 [30]. Among them, 3'-hexanoylamino-3'-deoxythymidine (9, Fig. 3) was identified as an inhibitor of dThd phosphorylation by TK2 with a $\mathrm{K}_{i}$ of $0.15 \mu \mathrm{M}$.

Later on, in 2000, different ribofuranosyl nucleoside analogues were reported as TK2 inhibitors (derivatives $\mathbf{1 0}$ and 11, (Fig. 3)), with $\mathrm{IC}_{50}$ values ranging from 4 to $19 \mu \mathrm{M}$ (Table 1) [31]. The most surprising finding was that, although $2^{\prime}$-deoxynucleoside BvdU (8) is an excellent substrate for TK2, its ribo analogue (10) is a rather poor substrate for TK2 but mainly behaved as a competitive inhibitor of thymidine phosphorylation by TK2.

One year later, in 2001, Manfredini et al. described the first family of arabinofuranosyl nucleosides as selective and effective TK2 inhibitors [32-34]. Within this series of compounds, the introduction of different lipophilic chains at the $2^{\prime}-\mathrm{OH}$ of AraT (6) and BvAraU (13a in Fig. 3) led to purely competitive inhibitors of TK2 with $\mathrm{IC}_{50}$ values in the micromolar range without a measurable effect on cytosolic TK1 (compounds 12, 13b and 14 in (Fig. 3) and Table 1). Again, by means of a simple chemical modification, good substrates of TK2 were converted into efficient TK2 inhibitors. These compounds were also tested against the related enzymes
HSV-1 TK and Dm-dNK. In contrast to the parent nucleosides AraT (6) and BvAraU (13a), compounds 12, 13b and 14 showed no particular effect on these enzymes. Further studies carried out with 12, the most active compound in these series, revealed that $\mathbf{1 2}$ was able to inhibit the TK2 enzyme "in organello" [34]. Still these 2'-Oacyl nucleosides are not ideal tools for studies in intact cells due to the esterase-sensitive acyl group, whose presence in the molecule is crucial for efficient TK2 inhibition [32].

It was in 2002 when our research groups described a unique family of acyclic nucleoside analogs as specific TK2 inhibitors. The starting point was the enzymatic evaluation of dThd phosphorylation by different dNKs in the presence of different nucleoside analogues synthesized in our laboratories as well as others derived from commercial sources. In this way $5^{\prime}-O$-tritylthymidine $(\mathbf{1 5}$, Fig. 4) was identified as a compound able to inhibit TK2 and HSV-1 TK activities with $\mathrm{IC}_{50}$ values of 33 and $7.8 \mu \mathrm{M}$, respectively [35]. The sole presence of the trityl group at position $5^{\prime}$ of the deoxyribose was able to convert the natural substrate thymidine into a TK2 inhibitor. It is not the aim of this review to detail all the synthesized compounds and the SAR studies that have been carried out within this family of analogs including their acyclic derivatives, and readers are referred to previous review articles [28, 29]. A brief summary containing the most relevant derivatives is here included. Their structures are collected in Figs. $\mathbf{4}$ and 5, and their enzymatic activities are displayed in Table $\mathbf{2}$. The working hypothesis consisted on the replacement of the sugar moiety of $5^{\prime}$ - $O$-tritylthymidine 15 by conformationally constrained acyclic spacers keeping the thymine base and the trityl group at each side of the spacer. Thus, introduction of a (Z)-butenyl spacer led to derivative 16 (Fig. 4), which showed a significant increase of the inhibitory activity against TK2 with an $\mathrm{IC}_{50}$ value of $1.5 \mu \mathrm{M}$, and this compound was considered as the lead for further optimizations [35].

The importance of the nucleic base was then explored by replacement of thymine with related pyrimidines such as 5-iodouracil or 5-(E)-(2-bromovinyl)uracil (BVU) as in compound 17 (Fig. 4) [36]. The latter compound showed similar activity against TK2 $\left(\mathrm{IC}_{50}=1.3 \mu \mathrm{M}\right)$ compared to $\mathbf{1 6}\left(\mathrm{IC}_{50}=1.5 \mu \mathrm{M}\right)$ but emerged as a

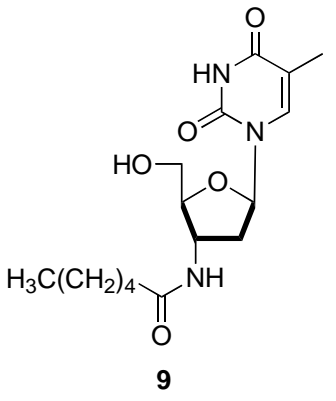<smiles>O=c1[nH]c(=O)n(C2OC(CO)C(O)C2O)cc1C=CBr</smiles><smiles>Cc1cn(C2C3OC(CO)C2(C(N)=CS(=O)(=O)O)O3)c(=O)[nH]c1=O</smiles>

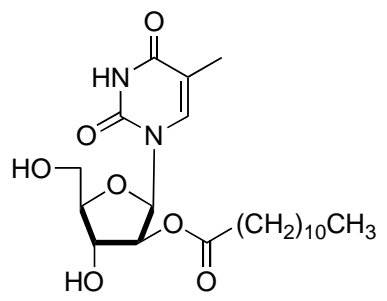<smiles>[R]OC1C2OC(CO)C(O2)C1O</smiles>

12

$$
\begin{aligned}
& 13 \text { a } \mathrm{R}=\mathrm{H} \text {, BvAraU } \\
& \text { b } \mathrm{R}=\mathrm{CO}\left(\mathrm{CH}_{2}\right)_{8} \mathrm{CH}_{3} \\
& 14 \mathrm{R}=\mathrm{CO}\left(\mathrm{CH}_{2}\right)_{10} \mathrm{CH}_{2} \mathrm{NHBoC}
\end{aligned}
$$

Fig. (3). Selected nucleoside derivatives reported as TK2 inhibitors. 
Table 1. Inhibitory Activity of Selected Nucleoside Derivatives on $\left[\right.$ methyl $\left._{-}{ }^{3} \mathrm{H}\right] \mathrm{dTHd}$ Phosphorylation by Different Deoxyribonucleoside Kinases

\begin{tabular}{|c|c|c|c|c|}
\hline \multirow[b]{2}{*}{ Compound } & \multicolumn{4}{|c|}{$\mathrm{IC}_{50}{ }^{\mathrm{a}}(\boldsymbol{\mu M})$} \\
\hline & TK1 & TK2 & HSV-1 TK & Dm-dNK \\
\hline $10^{\mathrm{b}}$ & $>1000$ & $19 \pm 1.1$ & - & - \\
\hline $11^{\mathrm{b}}$ & $>1000$ & $4.6 \pm 0.35$ & - & - \\
\hline $\operatorname{AraT}(7)^{c}$ & $>1000$ & $285 \pm 1$ & $24 \pm 3.1$ & $64 \pm 28$ \\
\hline $\operatorname{BvAraU}(13 a)^{c}$ & $>500$ & $43 \pm 5.8$ & $3.6 \pm 1.5$ & $28 \pm 10$ \\
\hline $12^{\mathrm{c}}$ & $\geq 1000$ & $28 \pm 2$ & $\geq 1000$ & $>1000$ \\
\hline $13^{\mathrm{c}}$ & $>1000$ & $6.8 \pm 0.7$ & $>1000$ & 163 \\
\hline $14^{c}$ & ND & $3.8 \pm 0.2$ & $>500$ & $\geq 500$ \\
\hline
\end{tabular}

${ }^{\mathrm{a}} 50 \%$ Inhibitory concentration required to inhibit phosphorylation of ${ }^{\mathrm{b}} 2 \mu \mathrm{M}$ or ${ }^{\mathrm{c}} 1 \mu \mathrm{M}$ [methyl-3H]dThd by $50 \%$. Data taken from references 31 and 34<smiles>Cc1cn(C2CC(O)C(COC(c3ccccc3)(c3ccccc3)c3ccccc3)O2)c(=O)[nH]c1=O</smiles>

15<smiles>Cc1cn(C/C=C\CN(Cc2ccccc2)Cc2ccccc2)c(=O)[nH]c1=O</smiles><smiles>Cc1cn(C/C=C\COC(c2ccccc2)(c2ccccc2)c2ccccc2)c(=O)[nH]c1=O</smiles>

16

Fig. (4). Selected TK2 inhibitors from the acyclic nucleoside derivative family.

highly selective inhibitor of TK2 because it completely lost inhibitory potency against HSV-1 TK and Dm-dNK (Table 4).

Next, replacement of the trityl ether moiety by different amines and carboxamides was explored while maintaining the thymine base and the (Z)-2-butenyl spacer [37]. Most of these compounds showed moderate inhibitory activity against TK2. The most relevant compounds among this series were the trityl amine derivative 19, which showed a profile similar to that of the $O$-trityl analogue 16, and the dibenzylamine derivative 18, which displayed a remarkable selectivity versus HSV-1 TK [37].

Alternatively, the trityl group and the thymine base were linked by a variety of polymethylene [38] or amide containing spacers [39]. The data obtained with polymethylene chains revealed a clear dependence between the length of the alkyl chain and the inhibitory potency against TK2, as exemplified by derivative $\mathbf{2 0}$ (Fig. 5), with a hexamethylene spacer, that was the most potent TK2 inhibitor with an $\mathrm{IC}_{50}$ of $0.5 \mu \mathrm{M}$. Keeping the thymine base and the hex- amethylene spacer, subtle modifications were performed at the trityl substituent. In particular, replacement of one of the phenyl rings of the trityl by a 4-pyridyl afforded a similarly potent TK2 inhibitor, designated as KIN109 (compound 21, Fig. 5), that has proved useful in further biological studies, as will be illustrated later. However, the corresponding $N$-methylpyridinium salt (22) was significantly less active against TK2. Another interesting example is compound 23 with a methyl carboxamide at position 4 of one of the phenyl rings of the trityl group. This compound has been shown to be the most potent inhibitor of TK2 within the acyclic nucleoside compound series. It should be stressed that all of these compounds were not inhibitory towards TK1 at concentrations up to $500 \mu \mathrm{M}$ and thus are endowed with an unprecedented selectivity against TK2.

Since our last report in 2008 [29], the research on TK2 inhibitors has been headed mainly by Van Calenbergh and collaborators who reported in 2009 a series of $3^{\prime}$-substituted thymidine derivatives as potent and selective inhibitors of human TK2 (Fig. 6) [40]. 
Table 2. Inhibitory Activity of Selected Acyclic Tritylated Nucleoside Derivatives on $\left[\right.$ methyl- ${ }^{3}$ H]dTHd Phosphorylation by Different Deoxyribonucleoside Kinases

\begin{tabular}{|c|c|c|c|c|}
\hline & \multicolumn{3}{|c|}{ IC $_{\mathbf{5 0}}{ }^{\mathbf{a}}(\boldsymbol{\mu M})$} \\
\hline Compound & TK1 & TK2 & HSV-1 TK & Dm-dNK \\
\hline \hline $\mathbf{1 5}$ & $>500$ & $33 \pm 20$ & $4.8 \pm 0.3$ & $3.3 \pm 0.9$ \\
\hline $\mathbf{1 6}$ & $>500$ & $1.5 \pm 0.2$ & $>500$ & $>500$ \\
\hline $\mathbf{1 7}$ & $>500$ & $1.3 \pm 1.1$ & $>500$ & $26 \pm 4$ \\
\hline $\mathbf{1 8}$ & $>500$ & $3.5 \pm 0.5$ & $3.7 \pm 0.5$ & $4.4 \pm 0.4$ \\
\hline $\mathbf{1 9}$ & $>500$ & $2.3 \pm 0.4$ & $2.0 \pm 0.4$ & $17 \pm 10$ \\
\hline $\mathbf{2 1}$ & $>500$ & $0.50 \pm 0.01$ & $41 \pm 6$ & $2.7 \pm 0.2$ \\
\hline $\mathbf{2 3}$ & $>500$ & $0.47 \pm 0.03$ & $23 \pm 1$ & $29 \pm 1$ \\
\hline
\end{tabular}

${ }^{\mathrm{a}} 50 \%$ Inhibitory concentration required to inhibit phosphorylation of $1 \mu \mathrm{M}[$ methyl-3H]dThd by $50 \%$. Data taken from references 35,37 and 38 .<smiles>Cc1cn(CCCCCCOC(c2ccccc2)(c2ccccc2)c2ccccc2)c(=O)[nH]c1=O</smiles><smiles>Cc1cn(CCCCCCOC(c2ccccc2)(c2ccccc2)c2ccncc2)c(=O)[nH]c1=O</smiles><smiles>Cc1cn(CCCCCCOC(c2ccccc2)(c2ccccc2)c2cc[n+](C)cc2)c(=O)[nH]c1=O</smiles><smiles>CNC(=O)c1ccc(C(OCCCCCCn2cc(C)c(=O)[nH]c2=O)(c2ccccc2)c2ccccc2)cc1</smiles>

Fig. (5). Structures of acyclic nucleoside derivatives bearing a hexamethylene spacer and distal modified groups.

Originally designed and evaluated as inhibitors of Mycobacterium tuberculosis thymidylate kinase (TMPKmt) [41], the 3'-thioureadThd derivatives 24-31(Fig. 6) showed moderate inhibition against this enzyme $\left(\mathrm{K}_{\mathrm{i}}: 5-67 \mu \mathrm{M}\right)$, and the authors decided to evaluate them against TK2, HSV-1 TK and TK1. As shown in Table 3, all thiourea derivatives potently inhibited $\mathrm{TK} 2$ with $\mathrm{IC}_{50}$ values ranging from 0.43 to $3.1 \mu \mathrm{M}$. It was also observed that the inhibitory activity was influenced by the nature of the aryl group present on the thiourea moiety. The 4-benzyloxyphenyl (27), 3,4-dichlorophenyl (29) or 4-chloro-3-trifluoromethylphenyl (28) derivatives afforded the best inhibitory activity, with significant selectivity for TK2 versus TK1 (selectivity index $\geq 1000$ ) and poor, if any, inhibitory activity against $\mathrm{HSV}-1 \mathrm{TK}\left(\mathrm{IC}_{50} 46-500 \mu \mathrm{M}\right)$. Moreover, compound $\mathbf{3 0}$ in which the thiourea substituent is connected directly to the sugar ring, was even more active against TK2 than the branched-chain analogue 28, while the replacement of the sulfur atom by an oxygen, as in derivative $\mathbf{3 1}$, led to a slightly less inhibitory activity against TK2 when compared to compound 30. It should be noticed that $\alpha$-nucleosides, as exemplified by the $5^{\prime}$-thiourea derivative 32 (Fig. 6, Table 3) [41], were 10-100 fold less potent than the 3 '-thiourea- $\beta$-dThd derivatives against TK2.

In order to increase the potency of the newly discovered 3'thiourea-thymidine derivatives, and based on the results of the molecular docking of compound $\mathbf{3 0}$ in the active substrate-binding site of TK2 (vide infra), the thiourea moiety was replaced by the bioisosteric 1,2,3-triazole group [42]. Therefore, several 1,4- and 1,5disubstituted-1,2,3-triazole derivatives were synthesized and evaluated (Fig. 7, Table 4). As in the thiourea series, the inhibitory activ- 


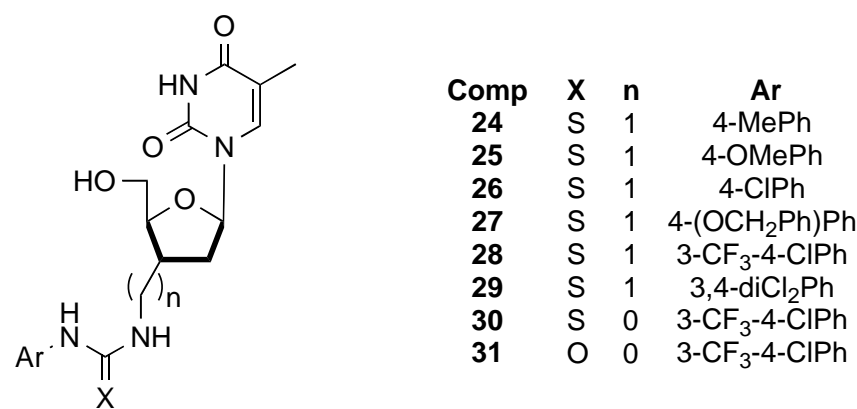<smiles>CC1=Cn2c(cc(=O)[nH]c2=O)CC1O</smiles>

32

Fig. (6). Structures of $3^{\prime}$-thiourea-dThd and $5^{\prime}$-thiourea- $\alpha$-dThd derivatives.

Table 3. Inhibitory Activity of $3^{\prime}$ - and $5^{\prime}-$ thiourea Derivatives on [methyl- $\left.{ }^{3} \mathrm{H}\right] \mathrm{dTHd}$ Phosphorylation by Different Deoxyribonucleoside Kinases

\begin{tabular}{|c|c|c|c|}
\hline Compound & \multicolumn{3}{|c|}{$\mathrm{IC}_{50}{ }^{\mathrm{a}}(\boldsymbol{\mu} \mathrm{M})$} \\
\hline 24 & $>500$ & $1.2 \pm 0.1$ & $444 \pm 18$ \\
\hline 25 & $>500$ & $3.1 \pm 0.3$ & $\geq 500$ \\
\hline 26 & $>500$ & $1.2 \pm 1.1$ & $400 \pm 54$ \\
\hline 28 & $\geq 500$ & $0.47 \pm 0.04$ & $46 \pm 4.0$ \\
\hline 29 & $\geq 500$ & $0.64 \pm 0.31$ & $87 \pm 36$ \\
\hline 30 & $316 \pm 1.2$ & $0.15 \pm 0.01$ & $195 \pm 54$ \\
\hline 31 & $416 \pm 6.0$ & $0.42 \pm 0.0$ & $335 \pm 25$ \\
\hline
\end{tabular}

${ }^{\mathrm{a}} 50 \%$ Inhibitory concentration required to inhibit phosphorylation of $1 \mu \mathrm{M}$ [methyl-3H]dThd by $50 \%$. Data taken from reference 40 .

ity was influenced by the nature of the substituent at C-4 of the triazole ring. Thus, compounds with an alkyl (34), a phenyl (35), a benzyl (36) or a cyclopentylmethyl (37) substituent afforded submicromolar $\mathrm{IC}_{50}$ values. Interestingly, the introduction of an electron-withdrawing $\mathrm{Cl}$ atom at the para position of the phenyl substituent, as in 38, significantly improved the anti-TK2 activity up to the nanomolar range. However, compound $\mathbf{4 0}$ (bearing a 2pyridinyl group) or the 1,5-triazoles $\mathbf{4 1}$ and $\mathbf{4 2}$ (regioisomers of $\mathbf{3 5}$ and 38, respectively) were much less potent. When thymine in derivatives $\mathbf{3 5}$ and $\mathbf{3 8}$ was replaced by BVU (well-known as a privileged base for the binding to TK2), the potency against TK2 was at least as good, if not slightly improved ( $\mathrm{IC}_{50}$ values $0.32 \mu \mathrm{M}$ for $\mathbf{3 5}$ vs. $0.25 \mu \mathrm{M}$ for $\mathbf{4 3}$ or $0.046 \mu \mathrm{M}$ for 38 vs. 0.036 for $\mathbf{4 4}$ ), whereas the selectivity against TK1 was significantly increased.

The most recent 3 '-substituted nucleoside derivatives described by Van Calenbergh and colleagues involve the incorporation of benzylamines, guanidine and (amino)tetrazole groups at the $3^{\prime}$ position (Figs. 8 and 9) [43]. In this limited series only benzyl, 4chlorophenyl and 4-chloro-3-trifluoromethylphenyl derivatives were synthesized on the basis of results obtained in the 1,2,3triazole series. In the case of (amino)tetrazole derivatives (Fig. 9), both thymine and BVU were used as the nucleic acid base. As shown in Table 5, the benzylamine (45-47) and guanidine (48-50) derivatives displayed inhibition of $\mathrm{TK} 2$ with $\mathrm{IC}_{50}$ values ranging from 0.33 to $4.6 \mu \mathrm{M}$. In all cases, the presence of a $3-\mathrm{CF}_{3}-4-\mathrm{Cl}$ substituted phenyl group (compounds 47 and 50) improved the TK2 inhibitory activity. The most potent inhibition was exhibited by the 1,5-aminotetrazole derivatives in which the tetrazole ring is attached to C3' via an $\mathbf{N H}$ bridge, as in compounds $\mathbf{5 1}$ and 53. The inhibitory potential of compounds $\mathbf{5 4 - 5 6}$ were clearly inferior to $\mathbf{5 1}$ and 53. To the best of our knowledge, compound $\mathbf{5 3}$, with an $\mathrm{IC}_{50}$ of $0.014 \mu \mathrm{M}$, emerged as the most potent and selective TK2 inhibitor reported to date [43].

\section{Kinetic Analysis of TK2 Inhibitors and Biological Studies}

In order to obtain additional information about the mode of TK2 inhibition by the compounds described, detailed kinetic analyses have been carried out with different series of compounds. 
Table 4. Inhibitory Activity of $3^{\prime}$-triazol-1-yl Derivatives of Thymidine and BVDU on [methyl- ${ }^{3}$ H]dTHd Phosphorylation by Different Deoxyribonucleoside Kinases

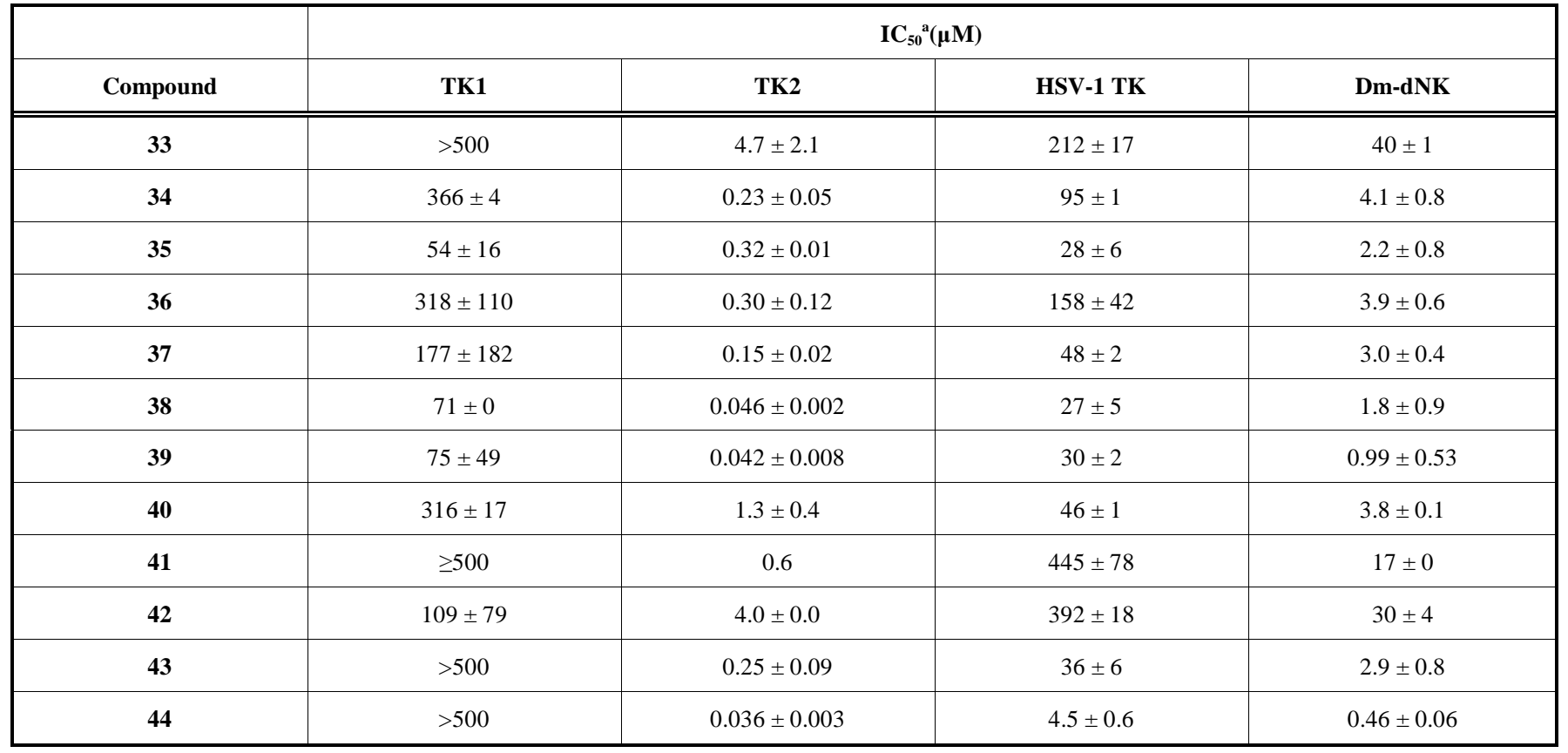

${ }^{\mathrm{a}} 50 \%$ Inhibitory concentration required to inhibit phosphorylation of $1 \mu \mathrm{M}[$ methyl-3H]dThd by $50 \%$. Data taken from ref. 42 .

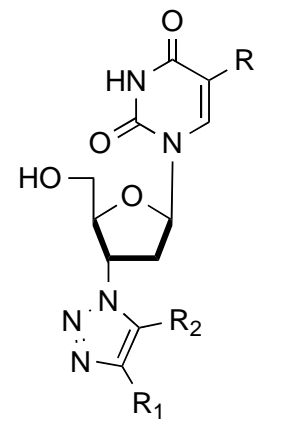

$\begin{array}{cc}\text { Comp } & \mathbf{R} \\ 33 & \mathrm{H} \\ 34 & \mathrm{H} \\ 35 & \mathrm{H} \\ 36 & \mathrm{H} \\ 37 & \mathrm{H} \\ 38 & \mathrm{H} \\ 39 & \mathrm{H} \\ 40 & \mathrm{H} \\ 41 & \mathrm{H} \\ 42 & \mathrm{H} \\ 43 & \text { (E)-(2-bromovinyl) } \\ 44 & \text { (E)-(2-bromovinyl) }\end{array}$

$\begin{array}{cc}\mathbf{R}_{\mathbf{1}} & \mathbf{R}_{\mathbf{2}} \\ \mathrm{H} & \mathrm{H} \\ \mathrm{nBu} & \mathrm{H} \\ \mathrm{Ph} & \mathrm{H} \\ \mathrm{CH}_{2} \mathrm{Ph} & \mathrm{H} \\ \mathrm{CH}_{2} \mathrm{Cyclopentyl} & \mathrm{H} \\ \text { 4-CIPh } & \mathrm{H} \\ \text { 3,4-diCl }{ }_{2} \mathrm{Ph} & \mathrm{H} \\ \text { 2-pyridinyl } & \mathrm{H} \\ \mathrm{H} & \mathrm{Ph} \\ \mathrm{H} & 4-\mathrm{CIPh} \\ \mathrm{Ph} & \mathrm{H} \\ \text { 4-ClPh } & \mathrm{H}\end{array}$

Fig. (7). General structure of the 3'-[4-Aryl-(1,2,3-triazol-1-yl) nucleoside analogue family.

Among the acyclic nucleoside derivatives, compounds 16, 17 [36] and 20 [38] were included in these assays. When evaluated against variable concentrations of thymidine (at saturating concentrations of ATP), these compounds behaved as competitive inhibitors of TK2 ( $\mathrm{K}_{\mathrm{i}}$ values of $0.50,0.78$ and $0.29 \mu \mathrm{M}$, respectively). On the other hand, if the variable substrate was ATP, uncompetitive inhibition was observed ( $\mathrm{K}_{\mathrm{i}}$ values of 17,24 and $10 \mu \mathrm{M}$, respectively). Thus it may be concluded that the acyclic nucleoside inhibitors occupy the thymidine binding site of TK2 only when the cosubstrate ATP is already bound to the enzyme.

As regards the $3^{\prime}$-substituted nucleosides, the kinetic properties of compounds 30 [40] and 38 [42] have also been investigated against TK2. When tested against variable concentrations of dThd, these inhibitors inhibited TK2 in a purely competitive fashion with considerable low $\mathrm{K}_{\mathrm{i}}$ values of 0.054 and $0.012 \mu \mathrm{M}$, respectively. In the presence of variable concentrations of ATP, the inhibitors displayed an uncompetitive behavior (as assessed by the parallel lines in the Linewaver-Burk kinetic plots) with $K_{i}$ values of 2 and 0.41 $\mu \mathrm{M}$, respectively. Therefore, also in this case, it seems that the compounds need the pre-formation of the TK2-ATP complex in order to interact with TK2 and exert their inhibition by occupying the thymidine-binding site.

Direct evaluation of TK2 inhibitors in cell culture is challenging. The mitochondrial localization of the enzyme and its relatively low expression levels, particularly in proliferating tissues where TK1 is far more abundant, really complicates the testing of TK2 inhibitors. Alternatively, on the basis of (i) the similarities between TK2 and other dNKs such as HSV-1 TK and Dm-dNK, and (ii) the fact that the most potent TK2 inhibitors also significantly inhibit Dm-dNK and/or HSV-1 TK, as illustrated in Tables 2-5, cell culture assays have been performed with cell lines transfected with these $\mathrm{dNK}$ s in the cytosol, but lacking the cytosolic TK1. In this respect, compounds 16, 20 and 21 were tested in OST-TK $/ \mathrm{HSV}-1 \mathrm{TK}^{+}$cell cultures (cells that lack TK1 and express HSV-1 TK in the cytosol) in the presence of efficient HSV-1 TK substrates such as Ara-T. The results obtained indicate that the acyclic nucleosides efficiently penetrate into the transfected cells and are able to reach their target enzyme in the intracellular environment when present in the cytosol $[35,38]$. 

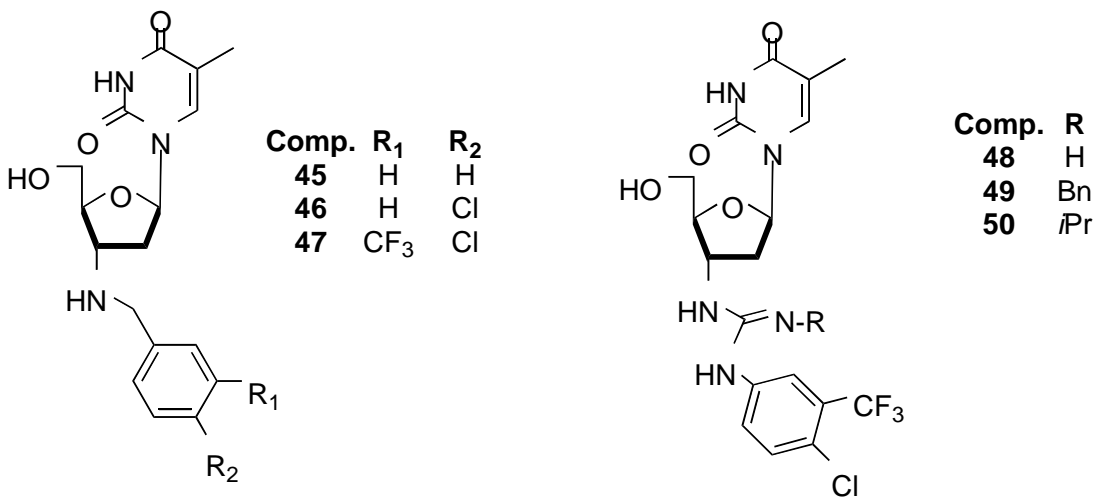

Fig. (8). Structure of the 3'-benzylamine and 3'-guanidine dThd and BvDU derivatives.<smiles>[R]c1cn(C2CC(Nc3nnnn3[R])C(CO)O2)c(=O)[nH]c1=O</smiles>

$\begin{array}{ccc}\text { Comp. } & \mathbf{R} & \mathbf{R}_{\mathbf{1}} \\ \mathbf{5 1} & \mathrm{H} & \text { 3-CF } \\ \mathbf{5 2} & \mathrm{H} & \text { Benzyl } \\ \mathbf{5 3} & \text { (E)-(2-bromovinyl) } & \text { 3-CF }-4-\mathrm{CIPh}\end{array}$<smiles>[R]Nc1nnnn1C1CC(n2cc([R])c(=O)[nH]c2=O)C(O)C1CO</smiles>

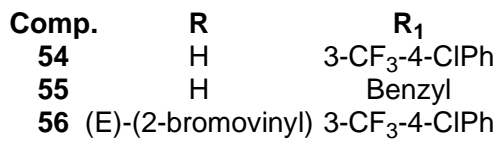

Fig. (9). Structure of the 1,5-aminotetrazole series of dThd and BvDU derivatives.

Similar experiments have been carried out with the $3^{\prime}$ substituted nucleosides, exemplified by compound 44 . In this case human osteosarcoma (OST TK${ }^{-}$) cells transfected with the $D m-d N K$ gene (OST TK$/ D m$-dNK ${ }^{+}$) were used. Cell cultures were exposed to these excellent $D m$-dNK substrates like BvdU in the presence or absence of 44. While BvdU was cytostatic against the $D m-\mathrm{dNK}^{+}$transfected cells at an $\mathrm{IC}_{50}$ of $0.76 \mu \mathrm{M}$, its antiproliferative effect was markedly decreased in the presence of $44[\sim 80 \%$ at $10 \mu \mathrm{M}$ $\left(\mathrm{IC}_{50} 2.95 \mu \mathrm{M}\right)$ and $\sim 50 \%$ at $4 \mu \mathrm{M}\left(\mathrm{IC}_{50} 1.64 \mu \mathrm{M}\right]$. Thus, under these experimental conditions, in the presence of the $D m$-dNK/TK2 inhibitor $\mathbf{4 4}$ the conversion of BvdU mediated by $D m$-dNK (expressed in the cytosol) was inhibited in a dose-dependent manner [42].

There are also reported examples where a specific TK2 inhibitor, KIN109 (21) in combination with radiolabeled $\left[{ }^{3} \mathrm{H}\right] \mathrm{BvdU}$, has been used as a tool to determine the TK1 and TK2 contribution to thymidine phosphorylation in different cell lines or during different phases of the cell cycle [44, 45]. In extracts from cycling cells KIN109 (21) did not inhibit dThd phosphorylation, demonstrating that TK1 is the predominant enzyme. In these same extracts, BvdU phosphorylation is affected by the presence of KIN109 (21) indicating that there is TK2 activity present in the proliferating cell cultures. However, in quiescent cells, KIN109 (21) efficiently inhibits both thymidine and BvdU phosphorylation confirming that TK2 is the predominant thymidine-phosphorylating enzyme under quiescence conditions [44]. Thus, $\left[{ }^{3} \mathrm{H}\right] \mathrm{BvdU}$ has been proposed as a suitable substrate to measure TK2 activity in cell extracts and the TK2 inhibitor KIN109 proved very helpful to discriminate between TK1 and TK2 enzyme activity levels. In fact, $\left[{ }^{3} \mathrm{H}\right] \mathrm{BvdU}$ and
KIN109 (21) have recently been successfully applied to measure TK2 activity in fibroblasts from two TK2-deficient patients with a slow progressing syndrome [45].

Despite the progress made in the synthesis and characterization of TK2 inhibitors, it is still unclear and even doubtful whether the available TK2 inhibitors are able to cross the double membrane of the mitochondria and reach the target enzyme TK2 in intact cells.

\section{D Homology Model for TK2 and Docking Studies}

Since the experimental resolution of the three-dimensional structure of TK2 remains elusive, construction of homology models still represents the most suitable tool to gain insight into the binding mode of the different families of enzyme inhibitors. Thus, the protein fold recognition method mGenTHREADER [46] was used to identify TK2's structural neighbours, which turned out to be the human enzymes deoxycytidine kinase (dCK), dGK and Dm-dNK, with sequence identities ranging from 17.7 to $47.7 \%$. More recent work using the Phyre2 server [47] has extended this structural similarity to HSV1 TK and equine herpesvirus type 4 TK. Sequence and structural alignment, as performed by Dali [48], are shown in Figs. $\mathbf{1 0}$ and 11, respectively. In common with these structural templates, the overall fold of TK2 is proposed to contain a three-layer $(\alpha \beta \alpha)$ sandwich architecture and a Rossmann fold. ATP and $\mathrm{Mg}^{2+}$ were also incorporated into the model since the reported enzyme kinetics for the described inhibitors indicated uncompetitive inhibition versus ATP, thus suggesting that the compounds bind to the enzymeATP complex. Additionally, the normal mode analysis of the initial constructed model of TK2 [37] revealed some interesting confor- 


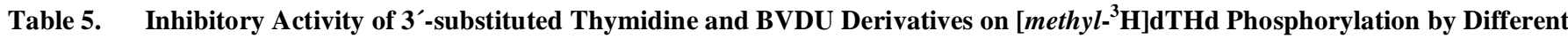
Deoxyribonucleoside Kinases

\begin{tabular}{|c|c|c|c|c|}
\hline & \multicolumn{3}{|c|}{ IC $_{\mathbf{5 0}}{ }^{\mathrm{a}}(\boldsymbol{\mu M})$} \\
\hline \hline Compound & $\mathbf{T K 1}$ & $\mathbf{T K 2}$ & HSV-1 TK & Dm-dNK \\
\hline \hline $\mathbf{4 5}$ & $>500$ & $4.6 \pm 0.3$ & $>500$ & $41 \pm 4$ \\
\hline $\mathbf{4 6}$ & $\geq 500$ & $3.3 \pm 0.2$ & $492 \pm 12$ & $4.8 \pm 0.2$ \\
\hline $\mathbf{4 7}$ & $442 \pm 37$ & $0.33 \pm 0.04$ & $>500$ & $11 \pm 6$ \\
\hline $\mathbf{4 8}$ & $355 \pm 69$ & $0.43 \pm 0.02$ & $372 \pm 39$ & $7.7 \pm 4.1$ \\
\hline $\mathbf{4 9}$ & $468 \pm 12$ & $1.3 \pm 0.5$ & $>500$ & $12 \pm 4$ \\
\hline $\mathbf{5 0}$ & $\geq 500$ & $0.58 \pm 0.29$ & $316 \pm 39$ & $1.2 \pm 0.0$ \\
\hline $\mathbf{5 2}$ & $382 \pm 52$ & $0.035 \pm 0.007$ & $>500$ & $10 \pm 6$ \\
\hline $\mathbf{5 3}$ & $>500$ & $0.90 \pm 0.01$ & $34 \pm 3$ & $0.41 \pm 0.04$ \\
\hline $\mathbf{5 6}$ & $>500$ & $0.014 \pm 0.001$ & $40 \pm 0$ & $3.6 \pm 0.7$ \\
\hline
\end{tabular}

${ }^{\mathrm{a}} 50 \%$ Inhibitory concentration required to inhibit phosphorylation of $1 \mu \mathrm{M}[$ methyl-3H]dThd by $50 \%$. Data taken from reference 43 . ----MLLWPLRGWAARALRCFGPGSRGSP ASGPGPRRVQRRAWPPDKEQEKEKKSVICV $------------M A E A A S C A R K G T K Y$ AEGTQP--------------------FTVLI MAAGRLFLSRLRAPFSSMAKSPLEGVSSSRGLHAG--------------- RGPRRLSI $* * * * . \quad * *: *:: \quad: \quad: \quad: \quad: * * * * \quad *: *: \ldots$ * * : **:: : EGN I ASGKT TCLEFF SN-ATDVEVL TEPVS KWRNVRGH-----------NPLGLMYHDA EGN I GSGKT TYLNHFE KY KND I CLL TEPVE KWRNVNGV-----------NLLELMY KDP EGN I AVGKS T FVKLLT KTYPEWHVA TEPVATWQN IQAAGT QKACT AQSLGNLLDMMYREP

:*. . : *: : *: *. : *

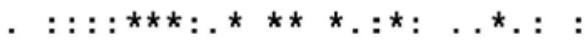
SRWGLTLQTYVQLTMLDRHTRP-------QVSSVRLMERS IH SARYIFVENLYRSGKMPE KKWAMP FQSYVT L TMLQSHTAP-------T NKKLKIMERS IF SARYCFVENMRRNGS LEQ ARWSYTFQTF SFLSRLKVQLEPFPE KLLQARKPVQI FERSVY SDRY I FAKNLFENGSLSD

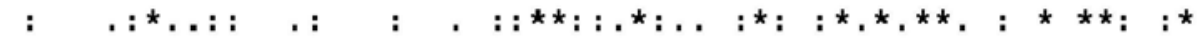
VDYVVLSEWFDWI LRNMD - -VSVDL IVYLRT NPETCYQRLKKRCREEEKVI PLEYLEAIH GMY NTLEEWY KF I EE S IH- -VQADL I I YLRT SPEVAYERI RQRARSEE SCVP LKYLQELH IEWHIYQDWHSFLLWEFASRI TLHGFIYLQASPQVCLKRLYQRAREEEKGI ELAYLEQLH

$$
\text { *****: }
$$

HLHEEWLI KG-----SLFPMAAPVLVI EAD HHMERMLELFEQNRDRI LTPENRKHCP --ELHEDWLI H------QRRPQSCKVLVLDAD LNLENI GTEYQR SES S I FDAI S SNQQP SPV GQHEAWLI HKTT KLHFEALMN I PVLVLDVNDDE SEEVTKQEDLMREVNT EVKNL------

\section{KI TM HUMAN \\ 25 DNK DROME \\ 43 DGUOK_HUMAN}

$\begin{aligned} 102 & \text { KI TM HUMAN } \\ 73 & \text { DNK_DROME } \\ 103 & \text { DGUOK_HUMAN }\end{aligned}$

155 KI TM HUMAN

126 DNK DROME 163 DGUOK HUMAN

\section{KI TM HUMAN \\ 184 DNK DROME 223 DGUOKR HUMAN}

\section{KI TM HUMAN 238 DNK DROME 277 DGUOK_HUMAN}

Fig. (10). Sequence alignment of TK2 and related enzymes.

mational changes involving the closure of the P-loop in the ATP binding site concomitant to the packing of $\alpha$-helices 3, 4, 6 and 7 . These changes provoked the appearance of a rather hydrophobic tunnel connecting the thymidine-binding pocket with the solvent at the interface between $\alpha$-helices 3, 5 and 8 and alternative side-chain orientations for Tyr99 and Tyr208 [38].
With these observations in hand, docking of the acyclic nucleoside derivative 20 was carried out (Fig. 12). The putative binding mode of $\mathbf{2 0}$ revealed that the thymine moiety occupied the thymidine-binding cavity with the heteroaromatic ring sandwiched between Phe143, Trp86 and Val115. This packing allowed O4 and $\mathrm{N} 3$ atoms of the pyrimidine ring to establish hydrogen bonds with the carboxamide group of Gln110. It should be noted that this inter- 


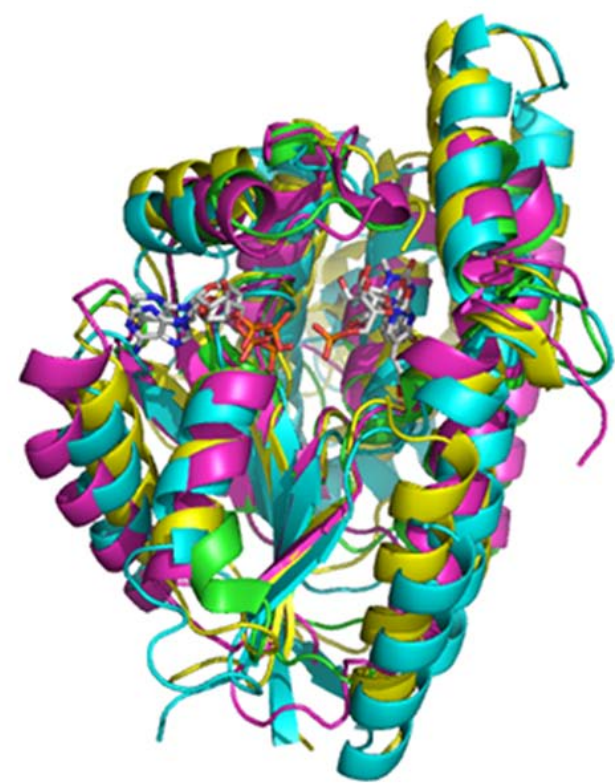

Fig. (11). Structural alignment, as performed by Dali ${ }^{48}$, of gemcitabine-bound Dm dNK (PDB id 2VPP, green), varicella zoster thymidine kinase in complex with BVDU-monophosphate and ADP (PDB id 1OSN, cyan), human dCK in complex with 2'-dC and ADP (PDB id 1P61, magenta), HSV6 TK in complex with $N$-methyl-dihydroxy-isobutyl-thymine (PDB id 3F0T, yellow), sulphate-bound HSV1 TK (PDB id 1E2H, salmon), and HSV1 TK in complex with dihydroxy-isobutyl-thymine (PDB id 1E2P, white).
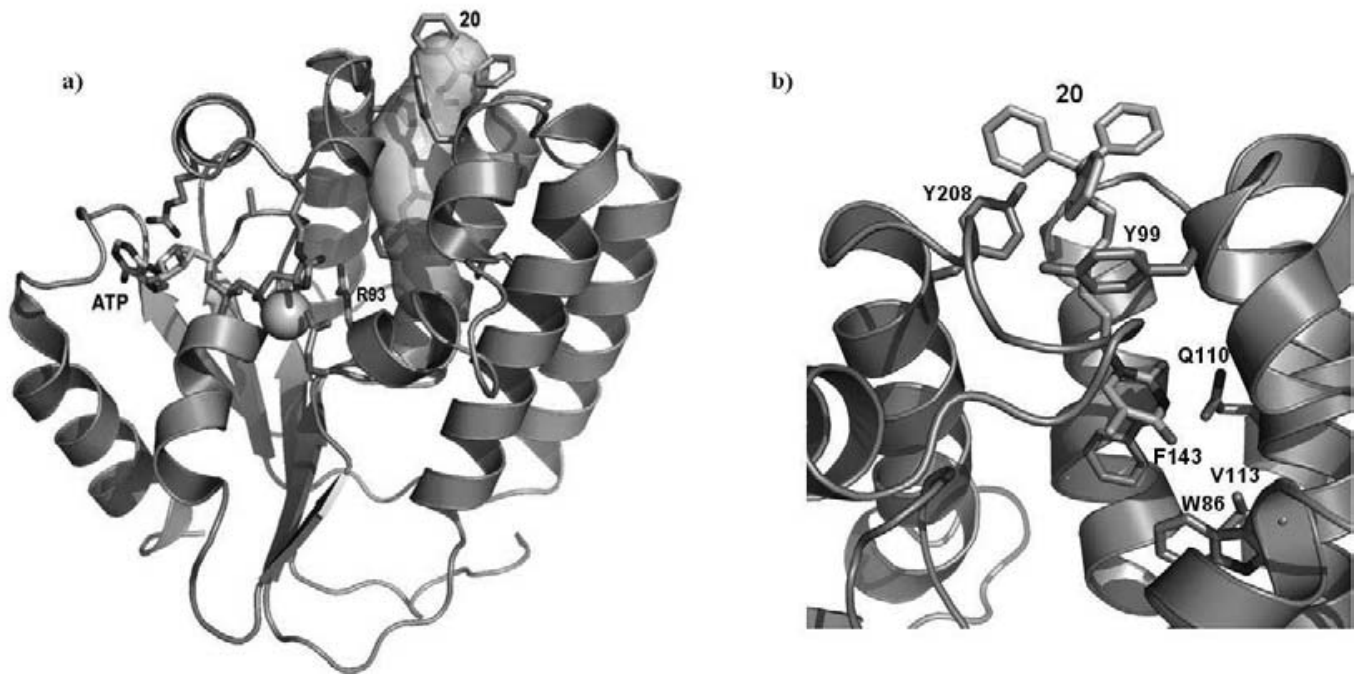

Fig. (12). (a) Squematic representation of the docking solution of acyclic nucleoside analogue 20 together with the tunnel (semitransparent surface), ATP and $\mathrm{Mg}^{2+}$ ion. (b) Closer look at the putative binding mode of 20 .

action pattern is proposed to be conserved for all thymine-containing inhibitors studied (see below). The hexamethylene spacer of 20 was placed along the hydrophobic tunnel and the trityl moiety was positioned so as to interact with Tyr99 and Tyr208. This model accounts for the SAR studies within these series of acyclic nucleoside inhibitors in so far as there is a critical spacer length below or above which interactions of the distal trityl group with the enzyme cannot take place and much lower TK2 affinities are observed.

Docking studies of some of the newest $3^{\prime}$-substituted-dThd analogues have also been carried out. Based again on the experimental data, inhibitor $\mathbf{3 0}$ was docked inside TK2 in the presence of bound ATP, and molecular dynamics simulations were carried out for the enzyme-inhibitor complex [40]. The final structure (Fig. 13) revealed the same features concerning the anchoring of the thymine base as observed for inhibitor 20, that is, stacking of the base with
Phe143, Trp86 and Val115 and two hydrogen bonds between $\mathrm{O} 4$ and $\mathrm{N} 3$ and the carboxamide group of $\mathrm{G} \ln 110$. Besides, the orientation of the sugar is such that the $5^{\prime}-\mathrm{OH}$ is fixed by the guanidinium nitrogen of Arg134. The substituted phenyl ring stacks against Ile59 and its orientation makes the trifluoromethyl group pointing to Arg196. More importantly, both thiourea nitrogens are hydrogenbonded to the $\gamma$-phosphate of ATP.

These new interactions between $\mathbf{3 0}$ and the cosubstrate ATP brought the attention to two major issues in the current model when addressing the docking of triazole derivative 38 [42], (i) the conformation of the C-terminal low-homology His-rich loop that stabilizes the adenine ring of ATP, and (ii) the precise side-chain conformation of the residues making up the "lid loop" that closes the entrance to the active site and stabilizes ATP and inhibitor binding. Through extrapolation from the available data from $D m$-dNK in 


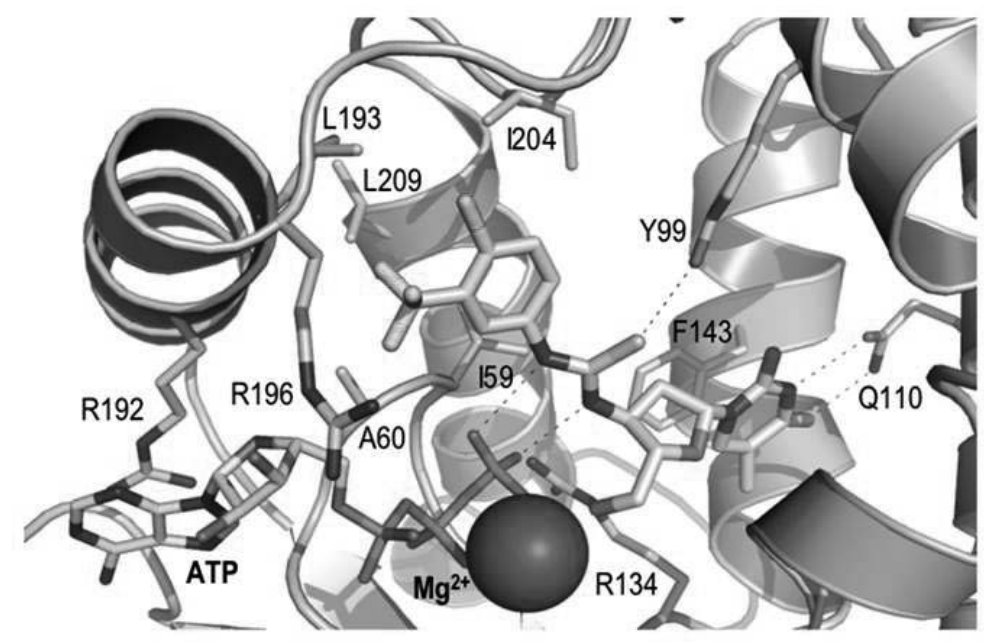

Fig. (13). Docking of the $3^{\prime}$-thiourea derivative 30. ATP and a $\mathrm{Mg}^{2+}$ ion are also shown.

complex with drugs, substrates and "feedback inhibiting" deoxyribonucleoside triphosphates, some conformational features were derived for TK2: (i) in the presence of bound ATP- $\mathrm{Mg}^{2+}$ the lid region must be found in a closed conformation with strong interactions between Glu200, Arg187 and Asn93, as well as between Glu201, Arg196 and Arg198. The latter Arg residues are also responsible for the anchoring of the $\alpha$ and $\beta$ phosphate groups of ATP, respectively; (ii) the $3^{\prime}-\mathrm{OH}$ of the thymidine substrate can be held in position by two direct hydrogen bonds with Glu201 and Tyr99, whose $\mathrm{OH}$ group is further anchored to a water molecule that bridges to Tyr208 and $\mathrm{O} 2$ of the thymine base; (iii) the presence of $\mathrm{Mg}^{2+}$ bound to the ATP phosphates promotes a small displacement of the side-chains of Glu81 and Glu133 so that, together with Thr64, these residues become part of the coordination sphere of the cation; and (iv) a free $5^{\prime}-\mathrm{OH}$ of a nucleosidic ligand can be hydrogen-bonded by the guanidinium nitrogen of Arg134 and the carboxamide group of Glu81, whose equivalent residues in $\mathrm{Dm}$ dNK have been shown to be crucial for the phosphoryl transfer reaction [49]. Taking all of these features into account, the docking solution obtained for derivative $\mathbf{3 8}$ is shown in (Fig. 14). As in previous studies, the thymidine moiety of $\mathbf{3 8}$ fills the substrate-binding site thus giving rise to the same interactions as described for deoxythymidine. In this location, the $\mathrm{C} 2{ }^{\prime}$-endo puckering of the sugar ring places the $3^{\prime}$-triazole ring with its nitrogens facing Glu200 and the phenyl ring forces the side-chain of Tyr99 to flip and also displaces the aforementioned water molecule. Interestingly, interaction with the carboxylate of Glu200 is mediated by a bridging water molecule that is also bonded to Arg198. As these two residues are part of the "lid loop", this arrangement can account for the fact that the loop is closed over the active site and therefore the ATP molecule can get trapped. Besides, the binding orientation of the triazole ring is fully compatible with the modulation of the inhibitory activity upon introduction of substituents at position 4 . Thus, the phenyl ring in 38 makes van der Waals interactions with Val203 and Ile204, and therefore occupation of this hydrophobic cavity leads to an increase in binding affinity.

Using the same methodology, the tetrazole derivatives were also docked in the model of ATP-bound TK2 [43]. It seemed clear that the closed loop conformation of the enzyme was better stabilized by the inhibitor having the amino group bridging the tetrazole ring to the sugar moiety. In the case of $\mathbf{5 1}$ (Fig. 15), the tetrazole moiety could interact with the guanidinium of Arg167 while the amino group could establish a hydrogen bond with the hydroxyl group of Tyr177. The structural equivalent of this Tyr177 in DmdNK is also a tyrosine (Tyr179) but in HSV-1 TK it is a methionine
(Met231), which cannot establish the mentioned hydrogen bond. This amino acid replacement may account for the fact that these compounds are much better inhibitors of TK2 and $D m$-dNK than of HSV-1 TK.

\section{Important Role of TK2 in mtDNA Maintenance and Potential Implications in Tumorigenesis}

As mentioned in the introduction, TK2 is a nuclear encoded mitochondrial enzyme that phosphorylates dThd and dCyd for mitochondrial DNA synthesis. Together with one other mitochondrial enzyme, dGK, TK2 catalyses the formation of deoxyribonucleotides required for DNA synthesis [20]. The importance of TK2 for mitochondrial DNA maintenance has been demonstrated in a mouse model deficient in TK2 [21]. The TK2-deficient mice develop normally during their first week of life but the following days they show growth retardation and progressive loss of mtDNA in multiple organs that is most pronounced in skeletal muscle, heart, brain and liver. In actively dividing cells several enzymes contribute to the synthesis of dNTPs that are used for both nuclear and mitochondrial DNA biogenesis and a specific deficiency of mitochondrial nucleoside kinases is therefore not symptomatic in S-phase cells. In actively dividing cells ribonucleotide reductase, thymidylate synthase and cytosolic TK1 play a major role in dNTP synthesis for both nuclear and mitochondrial DNA. However, when nuclear DNA replication is completed, one of the subunits of ribonucleotide reductase, the smaller R2 subunit, is rapidly degraded and also TK1 activity gets downregulated and is absent in quiescent cells [50]. The enzymes left to provide dNTPs for mitochondrial DNA replication in non-proliferating cells are TK2, dGK and an enzyme named p53R2, which replaces the ribonucleotide reductase R2 subunit but is present in much lower amounts compared to the $\mathrm{R} 2$ subunit. The compensatory enzymes present in quiescent cells are sufficient to provide dNTPs for mitochondrial DNA synthesis in certain cells like fibroblasts, with low levels of mtDNA, but not in cells from tissues with a high demand on mtDNA, like brain and muscle [51].

Deficient mtDNA synthesis is found in a group of severe genetic diseases collectively called mitochondrial DNA depletion syndromes (MDS). MDS entail multi-organ failure but can vary greatly in symptoms, age of onset and tissue-specificity [26]. In addition to MDS, alterations in mtDNA are important also in acquired human pathologies such as mitochondrial toxicity induced by HIV therapy that can manifest itself as severe clinical phenotypes [52]. It was indeed recently shown that patients treated with anti-retroviral nucleoside analogues accumulated mtDNA mutations caused by accelerated mtDNA turnover and a clonal expansion of 


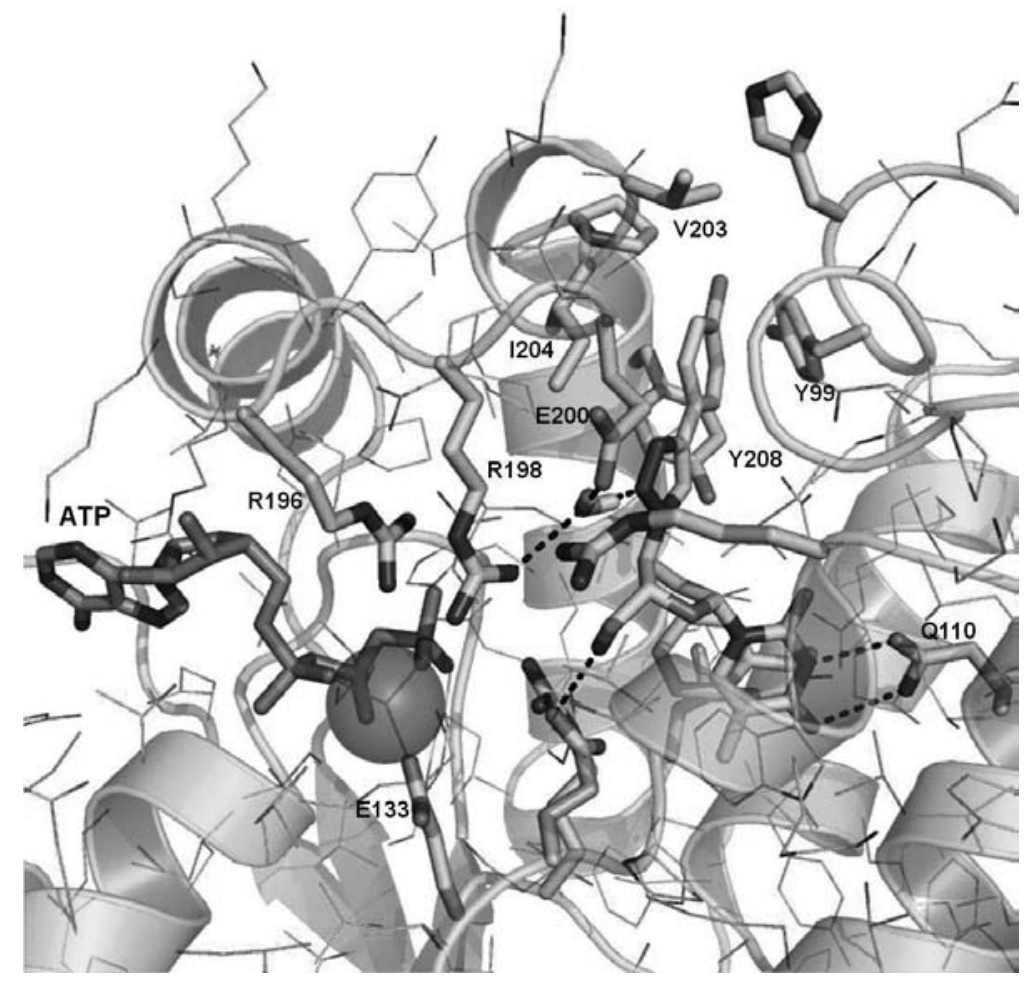

Fig. (14). Docking of the 3-triazole derivative 38. ATP and $\mathrm{Mg}^{2+}$ ion are shown on the left side of the enzyme, and the inhibitor on the right side.

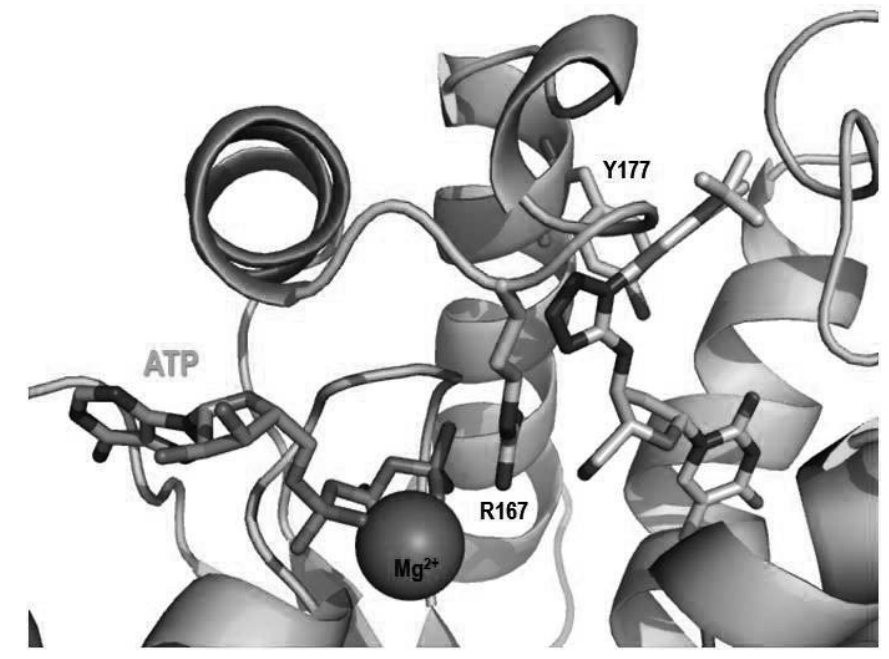

Fig. (15). Docking of the tetrazole derivative 51. ATP and $\mathrm{Mg}^{2+}$ ion are shown on the left side of the enzyme, and the inhibitor on the upper middle side.

preexisting age-related mtDNA mutations [53]. This was suggested to cause the premature aging phenotype frequently observed in drug-treated HIV-infected patients. If TK2 plays a role in the activation of these nucleoside analogues, it may be assumed that specific TK2 inhibitors could protect mtDNA from side-effects caused by those drugs, that inhibit the function of the mitochondrial DNA polymerase (pol $\gamma$ ), without affecting the antiviral efficiency of the compounds in the extra-mitochondrial compartments.

It would also be of interest to investigate TK2 inhibition in those diseases that are characterized by unwanted cell proliferation. The role of mitochondria, specifically mtDNA, in tumorigenesis remains largely unclear [54]. Decreased levels of mtDNA content have been detected in a variety of cancers such as breast cancer, renal carcinoma, hepatocellular carcinoma, and gastric tumors.
Furthermore, mtDNA is also depleted as a response to certain nucleoside analogues used in the treatment of malignant diseases. Thus, several studies suggest that depletion of mtDNA can be involved in tumorigenesis and may also occur in the treatment of cancer by certain nucleoside analogues. Previous studies have shown that certain organs, such as brain, skeletal muscle and liver, are completely dependent on TK2 for cell proliferation and tissue development [55]. Indeed, although the level of TK2 activity in brain tumors, sarcomas or liver tumors is not known, the TK2 dependence of the tissues from which these tumors originate make them prime candidates to study the effects of TK2 inhibition. With the altered ATP production in malignant cells they may be more vulnerable for TK2 inhibitors. In fact, malignant cells from tissues with high dependence on TK2 may indeed be even more sensitive 
to TK2 inhibition than the non-malignant cells, because the mitochondrial function is already turned down in malignant cells and thus the TK2 level for function is very close to the threshold level in the malignant cells, as compared to the non-malignant cells. Thus, the specificity of such TK inhibitors would rely on differences between adult differentiated cells as compared to transformed malignant cells. Available mouse models will be of interest to study the mtDNA synthesis in tumors and how tumors respond to mtDNA damage. In tissues less affected by TK2 deficiency, such as skin and hematopoetic cells, TK1 or ribonucleotide reductase activity can compensate for TK2 deficiency [56]. Whether these compensatory mechanisms are also valid for cancer cells originated from these tissues still remains to be proven. Cancer cells have a defective oxidative phosphorylation and usually prefer oxidation of fatty acids to produce ATP [57]. This property has been suggested to promote chemoresistance. Inhibition of mitochondrial function by TK2 inhibitors may deprive the cancer cells of ATP and induce tumor cell death. It still has to be investigated whether mtDNAdeficient cells are more susceptible to chemotherapy and other anticancer strategies. It is possible that the increased vulnerability that may be caused by TK2 inhibitors would facilitate other therapeutic approaches in cancer treatment.

\section{CONCLUSIONS}

TK2 turns out to be an important enzyme in several aspects. Since it provides phosphorylated pyrimidine nucleotides important for mitochondrial DNA synthesis, in particular in non-proliferating (resting) cells, it is therefore instrumental for the homeostasis of the mitochondrial nucleotide pools and mtDNA. TK2 deficiency results in the mitochondrial DNA depletion syndrome characterized by a reduced mtDNA copy number in several cell types. TK2 can also activate a variety of mitochondria-related antiviral and anti-cancer drugs, resulting in side-effects that could be potentially avoided if efficient TK2 inhibitors were available. Although highly potent and selective TK2 inhibitors have been designed and synthesized ( $\mathrm{Ki}$ in the nanomolar range; specific TK2 inhibition and no measurable TK1 inhibition), efficient uptake into the mitochondrial compartment of intact cells is still questionable and a challenge for future research and development of novel efficient TK2 inhibitors.

\section{ACKNOWLEDGMENTS}

Our research on TK2 inhibitors has been financed by the Spanish CICYT (SAF2006-12713-C02; SAF2003-07219-C02 and SAF 2000-0153-C02, to M.-J.P.-P., M.-J. C. and F. G.), the European Union (QLRT-2001-01004, to M.-J.P.-P., M.-J. C., A. K. and J. B.), and Comunidad de Madrid (S-BIO-0214-2006, to M.-J.P.-P., M.-J. C. and F. G.). Part of the research data discussed in this paper has been obtained thanks to the financial support of the K.U. Leuven to J. B. We would also like to thank those collaborators that have been involved in this joint project along these years.

\begin{tabular}{|c|c|c|}
\hline \multicolumn{3}{|c|}{ ABBREVIATIONS } \\
\hline TK & $=$ & Thymidine kinase \\
\hline$h T K$ & $=$ & Human TK gene \\
\hline dNTP & $=$ & 2'-deoxynucleoside-5' -triphosphate \\
\hline dThd & $=$ & (2'-deoxy)thymidine \\
\hline dUrd & $=$ & 2'-deoxyuridine \\
\hline dCyd & $=$ & 2'-deoxycytidine \\
\hline dGuo & $=$ & 2'-deoxyguanosine \\
\hline $\mathrm{AZT}$ & $=$ & 3'-azido-dThd \\
\hline dTMP & $=$ & dThd-5'-monophosphate \\
\hline dUMP & $=$ & dUrd-5'-monophosphate \\
\hline FLT & $=$ & 3'-fluoro-dThd \\
\hline AraT & $=$ & $1-\beta$-D-arabinofuranosylthymine \\
\hline
\end{tabular}

\begin{tabular}{|c|c|c|}
\hline FIAU & $=$ & $\begin{array}{l}\text { 1- } \beta \text {-D-(2’-fluoroarabinofuranosyl)-5- } \\
\text { iodouracil }\end{array}$ \\
\hline BvdU & $=$ & (E)-5-(2-bromovinyl)-2'-dUrd \\
\hline HIV & $=$ & Human immunodeficiency virus \\
\hline HSV & $=$ & Herpes simplex virus \\
\hline Dm-dNK & $=$ & $\begin{array}{l}\text { Drosophila melanogaster-deoxynucleoside } \\
\text { kinase }\end{array}$ \\
\hline dTTP & $=$ & dThd-5'-triphosphate \\
\hline MDS & $=$ & Mitochondrial DNA depletion syndrome \\
\hline ATP & $=$ & Adenosine-5'-triphosphate \\
\hline $\mathrm{K} i$ & $=$ & Inhibitory constant \\
\hline $\mathrm{dCK}$ & $=$ & dCyd kinase \\
\hline dGK & $=$ & dGuo kinase \\
\hline dNK & $=$ & 2'-deoxynucleoside kinase \\
\hline
\end{tabular}

\section{REFERENCES}

[1] Arner ESJ, Eriksson S. Mammalian deoxyribonucleoside kinases. Pharmacol Ther 1995; 67: 155-86.

[2] Eriksson S, Munch-Petersen B, Johansson K, Eklund H. Structure and function of cellular deoxyribonucleoside kinases. Cell Mol Life Sci 2002; 59: 1327-46.

[3] Van Rompay AR, Johansson M, Karlsson A. Substrate specificity and phosphorylation of antiviral and anticancer nucleoside analogues by human deoxyribonucleoside kinases and ribonucleoside kinases. Pharmacol Ther 2003; 100: 119-39.

[4] Deville-Bonne D, El Amri C, Meyer P, et al. Human and viral nucleoside/nucleotide kinases involved in antiviral drug activation: Structural and catalytic properties. Antiviral Research 2010; 86: 101-20.

[5] Munch-Petersen B. Enzymatic Regulation of Cytosolic Thymidine Kinase 1 and Mitochondrial Thymidine Kinase 2: A Mini Review. Nucleos Nucleot Nucl 2010; 29: 363-9.

[6] Bradshaw HD, Deininger PL. Human Thymidine Kinase Gene Molecular-Cloning and Nucleotide-Sequence of a Cdna Expressible in Mammalian-Cells. Mol Cell Biol 1984; 4: 2316-20.

[7] Flemington E, Bradshaw HD, Trainadorge V, Slagel V, Deininger PL. Sequence, Structure and Promoter Characterization of the $\mathrm{Hu}-$ man Thymidine Kinase Gene. Gene 1987; 52: 267-77.

[8] Hallek M, Wanders L, Strohmeyer S, Emmerich B. Thymidine kinase: a tumor marker with prognostic value for non-Hodgkin's lymphoma and a broad range of potential clinical applications. Annals of Hematology 1992; 65: 1-5.

[9] Romain S, Christensen IJ, Chinot O, et al. Prognostic value of cytosolic thymidine kinase activity as a marker or proliferation in breast cancer. Int J Cancer 1995; 61: 7-12.

[10] Chen Z, Zhou H, Li S, et al. Serological thymidine kinase 1 (STK1) indicates an elevated risk for the development of malignant tumors. Anticancer Res 2008; 28: 3897-908.

[11] Kim EY, Vrang L, Oberg B, Merigan TC. Anti-HIV type 1 activity of 3 '-fluoro-3 '-deoxythymidine for several different multidrugresistant mutants. Aids Res Hum Retrov 2001; 17: 401-7.

[12] Balzarini J, Baba M, Pauwels R, Herdewijn P, De Clercq E. Antiretrovirus activity of $3^{\prime}$-fluoro-substituted and $3^{\prime}$-azido-substituted pyrimidine 2',3'-dideoxynucleoside analogs. Biochem Pharmacol 1988; 37: 2847-56.

[13] Wettin K, Johansson M, Zheng XY, Zhu CY, Karlsson A. Cloning of mouse mitochondrial thymidine kinase 2 cDNA. FEBS Lett 1999; 460: 103-6.

[14] Wang L, Munch-Petersen B, Sjoberg AH, et al. Human thymidine kinase 2: molecular cloning and characterisation of the enzyme activity with antiviral and cytostatic nucleoside substrates. FEBS Lett 1999; 443: 170-4.

[15] Susan-Resiga D, Bentley AT, Lynx MD, LaClair DD, McKee EE. Zidovudine inhibits thymidine phosphorylation in the isolated perfused rat heart. Antimicrob Agents Chemother 2007; 51: 1142-9.

[16] Lynx MD, McKee EE. 3 '-azido-3 '-deoxythymidine (AZT) is a competitive inhibitor of thymidine phosphorylation in isolated rat heart and liver mitochondria. Biochem Pharmacol 2006; 72: 23943. 
[17] Welin M, Kosinska U, Mikkelsen NE, et al. Structures of thymidine kinase 1 of human and mycoplasmic origin. Proc Natl Acad Sci USA 2004; 101: 17970-5.

[18] Rampazzo C, Fabris S, Franzolin E, et al. Mitochondrial thymidine kinase and the enzymatic network regulating thymidine triphosphate pools in cultured human cells. J Biol Chem 2007; 282: 34758-69.

[19] Wang L. Deoxynucleoside Salvage Enzymes and Tissue Specific Mitochondrial DNA Depletion. Nucleos Nucleot Nucl 2010; 29: 370-81.

[20] Rampazzo C, Ferraro P, Pontarin G, et al. Mitochondrial deoxyribonucleotides, pool sizes, synthesis, and regulation. J Biol Chem 2004; 279: 17019-26.

[21] Zhou X, Solaroli N, Bjerke M, et al. Progressive loss of mitochondrial DNA in thymidine kinase 2-deficient mice. Hum Mol Genet 2008; 17: 2329-35.

[22] Hirano M, Marti R, Ferreiro-Barros C, et al. Defects of intergenomic communication: autosomal disorders that cause multiple deletions and depletion of mitochondrial DNA. Semin Cell Dev Biol 2001; 12: 417-27.

[23] Oskoui M, Davidzon G, Pascual J, et al. Clinical spectrum of mitochondrial DNA depletion due to mutations in the thymidine kinase 2 gene. Arch Neurol 2006; 63: 1122-6.

[24] Mancuso M, Salviati L, Sacconi S, et al. Mitochondrial DNA depletion - Mutations in thymidine kinase gene with myopathy and SMA. Neurology 2002; 59: 1197-202.

[25] Gotz A, Isohanni P, Pihko $\mathrm{H}$, et al. Thymidine kinase 2 defects can cause multi-tissue mtDNA depletion syndrome. Brain 2008; 131: 2841-50.

[26] Suomalainen A, Isohanni P. Mitochondrial DNA depletion syndromes - Many genes, common mechanisms. Neuromuscular Disord 2010; 20: 429-37.

[27] Saada A. Deoxyribonucleotides and disorders of mitochondrial DNA integrity. DNA Cell Biol 2004; 23: 797-806.

[28] Pérez-Pérez MJ, Hernández AI, Priego EM, et al. Mitochondrial thymidine kinase inhibitors. Curr Top Med Chem 2005; 5: 120519.

[29] Pérez-Pérez MJ, Priego EM, Hernandez AI, et al. Structure, physiological role, and specific inhibitors of human thymidine kinase 2 (TK2): Present and future. Med Res Rev 2008; 28: 797-820.

[30] Kierdaszuk B, Krawiec K, Kazimierczuk Z, et al. Substrate/inhibitor properties of human deoxycytidine kinase (dCK) and thymidine kinases (TK1 and TK2) towards the sugar moiety of nucleosides, including O '-alkyl analogues. Nucleos Nucleot 1999; 18: 1883-903.

[31] Balzarini J, Zhu CY, De Clercq E, et al. Novel ribofuranosylnucleoside lead compounds for potent and selective inhibitors of mitochondrial thymidine kinase-2. Biochem J 2000; 351: 167-71.

[32] Balzarini J, Degrève B, Zhu CY, et al. 2 '-O-acyl/alkyl-substituted arabinosyl nucleosides as inhibitors of human mitochondrial thymidine kinase. Biochem Pharmacol 2001; 61: 727-32.

[33] Manfredini S, Baraldi PG, Durini E, et al. Design, synthesis and enzymatic activity of highly selective human mitochondrial thymidine kinase inhibitors. Bioorg Med Chem Lett 2001; 11: 1329-32.

[34] Ciliberti N, Manfredini S, Angusti A, et al. Novel selective human mitochondrial kinase inhibitors: Design, synthesis and enzymatic activity. Bioorg Med Chem 2007; 15: 3065-81.

[35] Hernández AI, Balzarini J, Karlsson A, Camarasa MJ, Pérez-Pérez MJ. Acyclic nucleoside analogues as novel inhibitors of human mitochondrial thymidine kinase. J Med Chem 2002; 45: 4254-63.

[36] Balzarini J, Hernández AI, Roche P, et al. Non-nucleoside inhibitors of mitochondrial thymidine kinase (TK-2) differentially inhibit the closely related herpes simplex virus type $1 \mathrm{TK}$ and Drosophila melanogaster multifunctional deoxynucleoside kinase. Mol Pharmacol 2003; 63: 263-70

[37] Hernández AI, Balzarini J, Rodríguez-Barrios F, et al. Improving the selectivity of acyclic nucleoside analogues as inhibitors of human mitochondrial thymidine kinase: Replacement of a triphenylmethoxy moiety with substituted amines and carboxamides. Bioorg Med Chem Lett 2003; 13: 3027-30.
[38] Hernández AI, Familiar O, Negri A, et al. N-1-substituted thymine derivatives as mitochondrial thymidine kinase (TK-2) inhibitors. J Med Chem 2006; 49: 7766-73

[39] Priego EM, Balzarini J, Karlsson A, Camarasa MJ, Pérez-Pérez MJ. Synthesis and evaluation of thymine-derived carboxamides against mitochondrial thymidine kinase (TK-2) and related enzymes. Bioorg Med Chem 2004; 12: 5079-90.

[40] Balzarini J, Van Daele I, Negri A, et al. Human Mitochondrial Thymidine Kinase Is Selectively Inhibited by 3 '-Thiourea Derivatives of beta-Thymidine: Identification of Residues Crucial for Both Inhibition and Catalytic Activity. Mol Pharmacol 2009; 75: 1127-36.

[41] Van Daele I, Munier-Lehmann H, Froeyen M, Balzarini J, Van Calenbergh S. Rational design of 5'-thiourea-substituted alphathymidine analogues as thymidine monophosphate kinase inhibitors capable of inhibiting mycobacterial growth. J Med Chem 2007; 50: 5281-92.

[42] Van Poecke S, Negri A, Gago F, et al. 3 '-[4-Aryl-(1,2,3-triazol-1yl)]-3 '-deoxythymidine Analogues as Potent and Selective Inhibitors of Human Mitochondrial Thymidine Kinase. J Med Chem 2010; 53: 2902-12

[43] Van Poecke S, Negri A, Janssens J, et al. Synthesis, modeling and evaluation of 3 '-(1-aryl-1H-tetrazol-5-ylamino)-substituted 3 'deoxythymidine derivatives as potent and selective human mitochondrial thymidine kinase inhibitors. Org Biomol Chem 2011; 9: 892-901.

[44] Franzolin E, Rampazzo C, Pérez-Pérez MJ, et al. Bromovinyldeoxyuridine: A selective substrate for mitochondrial thymidine kinase in cell extracts. Biochem Biophys Res Commun 2006; 344 30-6.

[45] Frangini M, Rampazzo C, Franzolin E, et al. Unchanged thymidine triphosphate pools and thymidine metabolism in two lines of thymidine kinase 2-mutated fibroblasts. FEBS J 2009; 276: 110413.

[46] McGuffin LJ, Smith RT, Bryson K, Sorensen SAJ, D. T. High throughput profile-profile based fold recognition for the entire $\mathrm{Hu}-$ man proteome. BMC Bioinformatics 2006; 7: 288.

[47] Kelley LA, Sternberg MJE. Protein structure prediction on the Web: a case study using the Phyre server. Nature Protocols 2009; 4: 363-71.

[48] Holm L, Rosenstrom P. Dali server: conservation mapping in 3D. Nucleic Acids Res 2010; 38: W545-W9.

[49] Egeblad-Welin L, Sonntag Y, Eklund H, Munch-Petersen B. Functional studies of active-site mutants from Drosophila melanogaster deosyribonucleoside kinase. Investigations of the putative catalytic glutamate-arginine pair and of residues responsible for substrate specificity. FEBS J 2007; 274: 1542-51

[50] Hakansson P, Hofer A, Thelander L. Regulation of mammalian ribonucleotide reduction and dNTP pools after DNA damage and in resting cells. J Biol Chem 2006; 281: 7834-41.

[51] Pontarin G, Ferraro P, Rampazzo C, et al. Deoxyribonucleotide Metabolism in Cycling and Resting Human Fibroblasts with a Missense Mutation in p53R2, a Subunit of Ribonucleotide Reductase. J Biol Chem 2011; 286: 11132-40.

[52] Apostolova N, Blas-García A, Espluques JV. Mitochondrial toxicity in HAART: an overview of in vitro evidence. Curr Pharm Design 2011; 17: 2130-44.

[53] Payne BAI, Wilson IJ, Hateley CA, et al. Mitochondrial aging is accelerated by anti-retroviral therapy through the clonal expansion of mtDNA mutations. Nat Genet 2011; 43: 806-U121.

[54] Lu J, Sharma LK, Bai Y. Implications of mitochondrial DNA mutations and mitochondrial dysfunction in tumorigenesis. Cell Research 2009; 19: 802-15.

[55] Bartesaghi S, Betts-Henderson J, Cain K, et al. Loss of thymidine kinase 2 alters neuronal bioenergetics and leads to neurodegeneration. Hum Mol Genet 2010; 19: 1669-77.

[56] Zhou X, Johansson M, Solaroli N, et al. Hematopoiesis in the thymidine kinase 2 deficient mouse model of mitochondrial DNA depletion syndrome. J Inherit Metab Dis 2010; 33: 231-6.

[57] Samudio I, Fiegl M, Andreeff M. Mitochondrial Uncoupling and the Warburg Effect: Molecular Basis for the Reprogramming of Cancer Cell Metabolism. Cancer Res 2009; 69: 2163-6. 